\title{
Deep Hardening of Inner Cylindrical Surface by Periodic Deep Rolling - Burnishing Process
}

\author{
I. M. Gryadunov ${ }^{1}$, S. Yu. Radchenko ${ }^{1}$, D. O. Dorokhov ${ }^{1} \&$ P. G. Morrev ${ }^{1}$ \\ ${ }^{1}$ State University, Education-Science-Production Complex, Oryol, Russia \\ Correspondence: I. M. Gryadunov, State University-Education-Science-Production complex, Orel, Russia. \\ E-mail: fry14@yandex.ru
}

Received: October 22, 2014

Accepted: February 3, 2015 Online Published: August 30, 2015

doi:10.5539/mas.v9n9p251

URL: http://dx.doi.org/10.5539/mas.v9n9p251

The research is financed by Ministry of Education and Science of Russian Federation.

\begin{abstract}
Severe surface plastic deformation is one of the methods to improve the mechanical behavior of metallic components, because such a treatment generates a hardened near-surface layer with compressive residual stresses. As is well known, deep rolling (DR) stands out against a background of the others mechanical techniques owing to maximum values of hardness, residual stress and hardening depth attained. In this work, an accomplished version of DR is proposed, which may be regarded as a superposition of $\mathbf{D R}$ and burnishing (B) processes in order to elevate those characteristics up to larger values. In contrast to consecutive application of $\mathbf{D R}$ and $\mathbf{B}$ techniques, the new approach allows to alter them multiply within one and only technological process with no increasing the working duration and without the need of any additional equipment. The working principles of the device are described. The dependences "depth-hardness" are presented. Numerical assessment of the residual stress is performed. The micro-photographies demonstrate an increase in the structural homogeneity of the near-surface layer material. The results indicate that the newly developed technique attains its main goals.
\end{abstract}

Keywords: surface hardening, deep rolling, burnishing, residual stress, microstructure

\section{Introduction}

Surface affects the impotant characteristics of metallic components: resistance to plastic deformation (surface hardness), resistance to corrosion, fatigue fracture, fretting fatigue, and wear, because most cases of material failure originate from the exterior layers of the workpiece [1]. If surface experiences mechanical contact loads, the role of those characteristics grows dramatically.

Severe surface plastic deformation is an effective way to improve the surface behavior and the three most popular techniques are: shot peening (SP) [2-5], burnishing (B) [6-9], and deep rolling (DR) [10-14]. All of them provide similar effects: grain refinement, hardening and compressive residual stress, but there exist essential distinctions. The main feature of SP is the applicability to workpieces of complex geometry, but essential problems occur when dealing with inner surfaces of small size. In such case, B and DR are good alternatives. Burnishing is used as a finishing procedure and provides with high quality treatment in terms of surface roughness. Problem arises when dealing with surface of complex geometry. DR stands out against a background of the others (both mechanical and many non-mechanical) techniques owing to large values of hardness, residual stress and hardening depth attained. Unfortunately, the problem of complex geometry comes on again: whereas an axial symmetric workpiece can be wrought by means of a turning lathe, in more intricate cases, robot is selected as the machine platform [15].

So, SP, B, and DR techniques complement one another and their combinations may give an essential benefit. In this work, a new technique (DRB) is proposed, which may be regarded as a superposition of DR and B. It means that DR and B alternate multiply; this feature permits to elevate the values of hardening and hardening depth in comparison to DR. In contrast to B, which is performed with lower pressures and mainly serves to achieve a high surface quality, the aim of DRB treatment is to induce deep work hardening surface layers with compressive residual stresses. It should be pointed out that severe plastic deformation may be effective in powder technology applications [16]. Therefore, DRB has a good perspective in that field also. 
Before to present the working principles, the experimental data, and the numerical simulation results some remarks should be done. First of all, the surface characteristics under consideration (all of them were aforesaid in the beginning of the paper) are affected by both B and DR working via process parameters such as: rolling (burnishing) speed, pressing force, feed rate, number of passes, roller (ball) material and size, lubricant, temperature, etc.. But, proper dependencies are too complicated because the local deforming process is too complicated on its own account due to the fact that it may be accompanied not only by high gradient values of stress and stain tensors but also by essential transformations of the material microstructure. For example, the hardness profile beneath the surface of hardened cold working die steel was assessed in [17] and it was noticed that its value increased with applied force, nevertheless, its influence on the depth of the affected zone was minimal, moreover, the amount of retained austenite decreased after deep rolling (as a result of martensite transformation) and contributed, together with strain hardening, to the elevation of hardness. One more interesting example is surface hardening by cryogenic DR [18], where DR working under low temperature elevated the hardness profile.

It is known that the effect of both B and DR grows as number of passes $n$ increases, but the typical value is $n=1-5$. The reason is that $\mathrm{n}$ is limited by the crack generation. Thereby, a natural issue comes on: is it possible to increase number of passes if to combine B and DR processes? The overall aim of the present paper is to resolve this issue. The paper examines the use of the periodic deep rolling - burnishing process to improve inner cylindrical surface characteristics such as surface microhardness and compressive residual stress for cast bronze using turning lathe machine. The effect of two DRB parameters, namely, number of passes and feed rate on the in-depth hardness profile was studied. The stress tensor hydrostatic component profile was calculated. The microstructure photographies of the virgin material and the wrought one were obtained.

\section{Material Studied and Experimental Technique}

The work material is cast bronze $(5 \% \mathrm{~Pb}, 5 \% \mathrm{Zn}, 5 \% \mathrm{Sn}, 85 \% \mathrm{Cu})$, which is commonly used in bush bearing manufacturing. It should be noted, the material is too hard for cold working and the only way to fulfill such a treatment is to create sufficiently large compressive stresses in the course of the process. DRB technique permits to attain the necessary compression value. The blanks were obtained by means of further lathe treatment. The inner and outer radii, and the length are $50 \mathrm{~mm}, 70 \mathrm{~mm}$, and $50 \mathrm{~mm}$ respectively. Surface hardness measurements were conducted using microhardness tester Anton Paar MHT-10 (Anton Paar GmbH ). Microphotography was done by microscope AXIOSCOP 2 MAT (Carl Zeiss). The specimens for micro-photo-analyses were prepared by grinding and polishing, followed by etching in a water solution of 5\% $\mathrm{FeCl}_{3}$ and $10 \% \mathrm{HCl}$.

The idea of DRB working is shown in Figure 1a, where a perfect case of periodic deformation is depicted. In practice, deformation is not quite periodic and grooves appear on the surface treated - see Section 4.1. The workpiece is put into container to provide with compressive stresses in the course of treatment and hence to prevent the phenomenon of rolling out. The DRB tool operates with three equally spaced steel rollers - one deforming and two burnishing (Figure 1b). The deforming roller has a chamfered fillet of width $1 \mathrm{~mm}$ to indent the surface. The device structure provides for equal pressing forces $F$ on all three rollers. They can rotate about the device axe $O$ and also about their own axes $O_{1}, O_{2}, O_{3}$. The rollers are conical to give the opportunity of regulating the indentation depth for the deforming roller. Figure 1c shows DRB tool (axial profile $O O_{1}$ in Figure 1b) in details designed and made to perform the experiments. Bolts $4 \mathrm{a}$ and $4 \mathrm{~b}$ regulate the indentation depth by means of the deforming roller impress size on the wrought surface. All three rollers can roll along conical supports $8 \mathrm{a}$ and $8 \mathrm{~b}$, while support $8 \mathrm{~b}$ can rotate about support $8 \mathrm{a}$. Lock-nuts $5 \mathrm{a}$ and $5 \mathrm{~b}$ fix bolts $4 \mathrm{a}$ and $4 \mathrm{~b}$ in the position needed. DRB device is mounted on the turning lathe (Figure 2).

The indentation depth was fixed at value $0.2 \mathrm{~mm}$ for all experiments. It is known that only optimized rolling force (depth) can increase the fatigue strength, too low force (depth) has no profound influence on the fatigue behavior and too high one may even aggravate it by inducing micro-cracks $[19,20]$. Feed rate $r$ was equal 0.5 , 0.7 , and $1.0[\mathrm{~mm} / \mathrm{rev}]$. The point is that at rate $r<0.5[\mathrm{~mm} / \mathrm{rev}]$ the surface cutting effect does occur, while at rate $r>1[\mathrm{~mm} / \mathrm{rev}]$ the deforming roller trace does not overlap. Number of passes $n$ was altered from $n=15$ up to $n=30$. Microphotographies of the wrought material correspond to the following process parameters: $n=15$, $r=0,5[\mathrm{~mm} / \mathrm{rev}]$. Table 1 shows the arrangements and some results of the 6 experiments that were performed.

\section{Residual Stress Simulation}

To find the residual stress after the course of surface cold working, many investigators applied to numerical simulations. Both 2-D and 3-D modeling were exploited. The main disadvantage of 2-D modeling is inability to calculate the tangential component of the residual stress. At the same time, that component is about one third of 
the axial one if to compare the maximum values $[19,21]$ and one of the goals of this work is to assess the latter satisfactorily. The results on ball burnishing modeling [22] indicate that the difference between calculated and measured residual stress values vary by $40 \%$ for $2 \mathrm{D}$ simulation and by $7 \%$ for $3 \mathrm{D}$ one. According to that work, the plane strain assumption for 2D model prohibits the material from flowing along the out-of-plane tangential direction, and thus, compared to 3D simulations, the plastic strain decreases clearly. Consequently, the maximum residual stress introduced is affected. As for DRB simulation, the results [22] should be corrected. Indeed, the contact zone for the deforming roller (see Figure 1b) in DRB process is of the oval form and plastic flowing in tangential direction is far less than in axial one. Hence, the error of axial stress $2 \mathrm{D}$ calculations must be not as large as $40 \%$. In addition, DRB working permits a large number of passes. Therefore, 3-D calculation is too time-expensive. Due to all the above, 2-D simulation was preferred. At the same time, the comparison with 3D numerical model is necessary in further investigations (at least, for small number of passes) to validate the results presented in Section 4.3.

Table 1. Experimental design matrix and the results of surface topography

\begin{tabular}{cccccc}
\hline Exp. no & Feed rate, $\mathrm{mm} / \mathrm{rev}$ & Number of passes & $\begin{array}{l}\text { Initial out-of- } \\
\text { roundness, } \mu \mathrm{m}\end{array}$ & $\begin{array}{l}\text { Final out-of- } \\
\text { roundness, } \mu \mathrm{m}\end{array}$ & $\begin{array}{l}\text { Groove's depth, } \\
\mu \mathrm{m}\end{array}$ \\
\hline 1 & 0,5 & 15 & 11 & 19 & 21 \\
2 & 0,5 & 20 & 10 & 13 & 17 \\
3 & 0,5 & 25 & 3 & 16 & 12 \\
4 & 0,5 & 30 & 7 & 12 & 19 \\
5 & 0,7 & 20 & 3 & 32 & 43 \\
6 & 1,0 & 20 & 6 & 30 & 76 \\
\hline
\end{tabular}

(a)

(b)
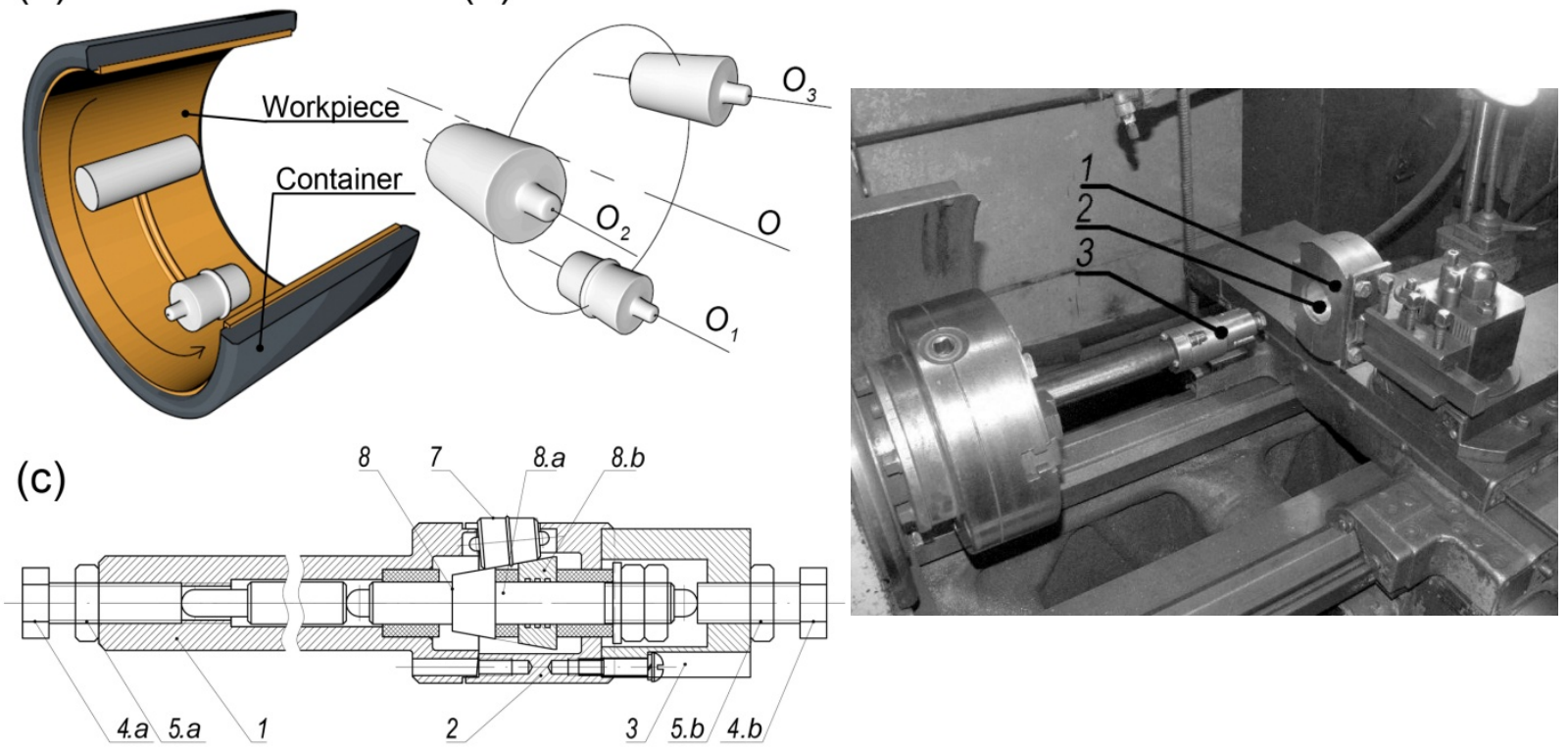

Figure 1. a Schematic illustration of DRB process, b A spatial view of the rollers, and c A detailed view of the DRB tool

Figure 2. Experimental setup: (1) Container, (2) Workpiece, and (3) DRB tool

\section{Results and Discussion}

\subsection{Surface Topography}

Optical images of the treated surface under different feed rates are presented in Figure 3. One can see that 
deformation is not quite periodic as it is shown in Figure 1a, but this feature may be an advantage in some cases because groove appearance on the treated surface means higher capacity for lubricant retention. In principle, one can regulate groove's depth by re-distribution of pressing forces on the rollers (Figure 1b), but this is a subject of further investigations. Figure $3 \mathrm{~b}$ shows that number of passes $n$ can attain $n \approx 30$, whereupon the workpiece begins to be damaged. The maximum number of passes is limited by damaging and hence is affected by the experimental conditions, but in this work, such dependence is not investigated. The experimental data on out-of-roundness $\delta$ and $\Delta$ (before and after working respectively) and groove's depth $g$ are represented in Table 1 . It is interesting to point out that $\Delta$ does not depend on $\delta$ in the experiment arrangements, but $\Delta$ depends on feed rate $r$ apparently. As for groove's depth, one can see that at constant feed rate, $g$ diminishes versus $n$ down to 12 $\mu \mathrm{m}$, whereupon increases up to $19 \mu \mathrm{m}$, when the material begins to be damaged. Besides, $g$ depends appreciably on $r$.

The main result reported in this Subsection is the maximum number of passes attained in the experiments exceeds all known data on $\mathbf{B}$ and DR techniques.
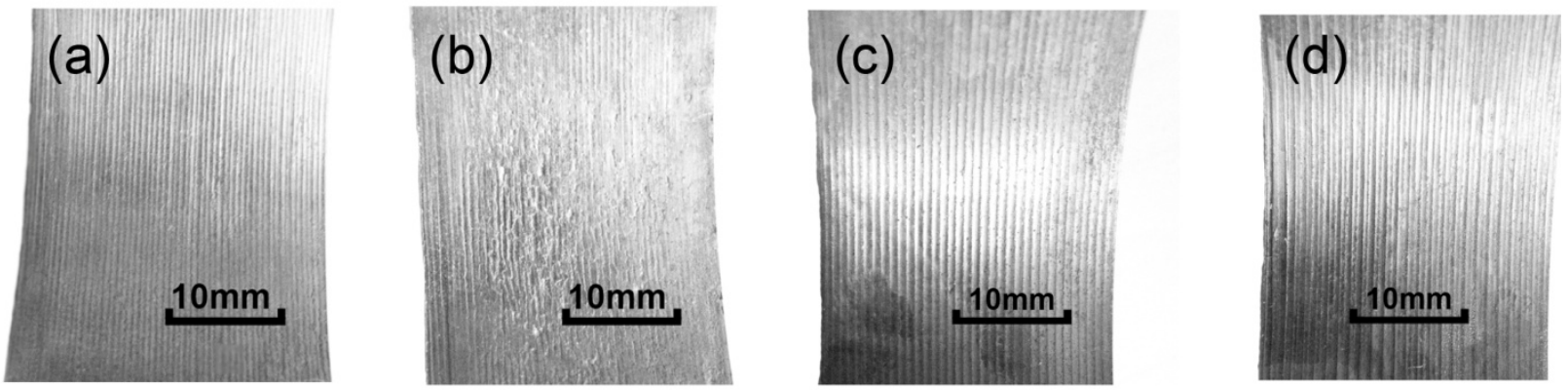

Figure 3. Effect of number of passes $n$ and feed rate $r$ on surface view:

a $15 \leq n \leq 25, r=0.5[\mathrm{~mm} / \mathrm{rev}], \mathbf{b} n \geq 30, r=0.5[\mathrm{~mm} / \mathrm{rev}], \mathbf{c} n=20, r=0.7[\mathrm{~mm} / \mathrm{rev}]$, and $\mathbf{d} n=20, r=1.0[\mathrm{~mm} / \mathrm{rev}]$

\subsection{Surface Microhardness}

Microhardness was measured in the crosswise section (i.e., normal to $O$ axis in Figure $1 \mathrm{~b}$ ). The in-depth profiles for treated surfaces are shown in Figure 4, 5.

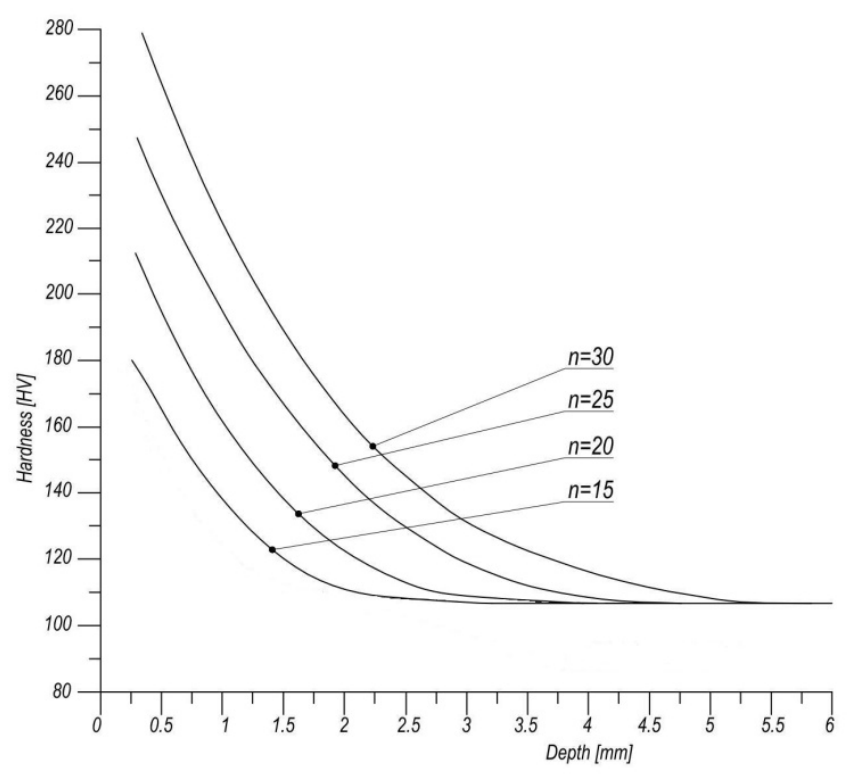

Figure 4. Effect of number of passes $n$ on in-depth hardness profile at constant feed rate $r=0.5$ [mm/rev] 


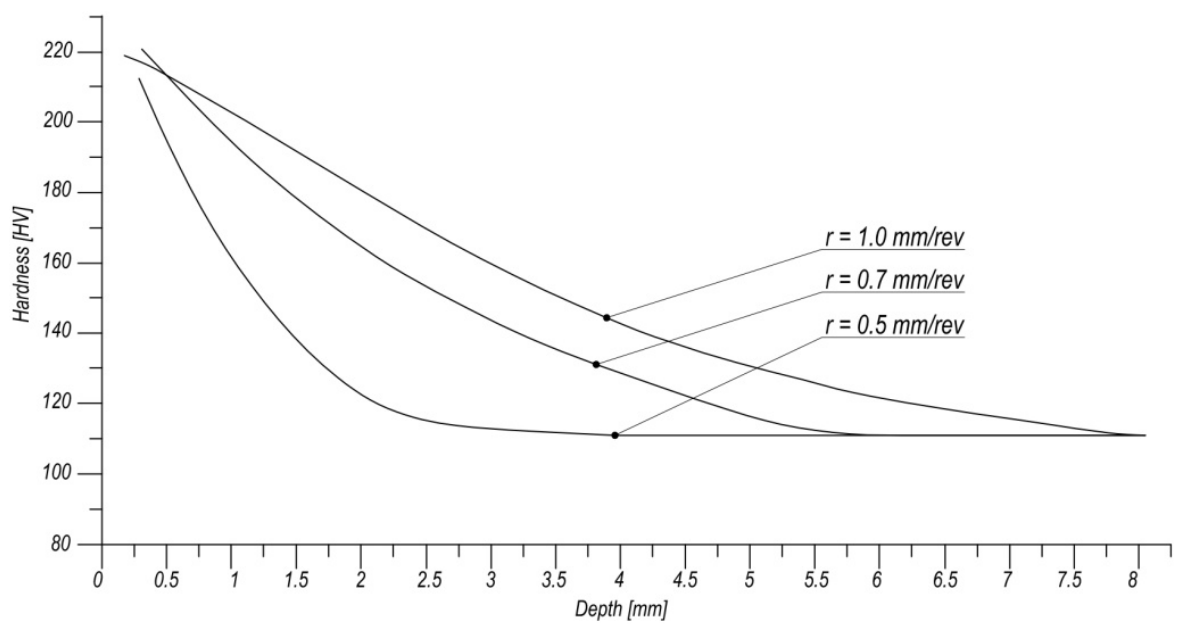

Figure 5. Effect of feed rate $r$ on in-depth hardness profile at constant number of passes $n=20$

Figure 4 depicts the dependence of microhardness profile on number of passes $n$ and Figure 5 - on feed rate $r$. The experimental points in both figures (number of points was altered from 12 up to 32 versus the experiment number in Table 1) are omitted in order to avoid excessively complicated patterns. The work-hardened layer depth ranges from $2 \mathrm{~mm}$ to $5 \mathrm{~mm}$; beyond this layer hardness remains almost unaffected. Such the hardening depth values exceed corresponding data for all others surface hardening techniques. It is seen in Figure 4 that the hardening gradient is not affected by $n$, but the surface hardness increasing and the hardening depth are approximately proportional to $n$. Figure 5 demonstrates the opportunity to govern the hardness gradient by means of feed rate $r$ altering.

\subsection{Residual Stress Simulation}

To solve the appropriate contact problem, the approach [23] was used. The irregular finite element mesh consists of 1922 three-node linear triangles. For in case of 2-D numerical simulation a solution of high accuracy is not expected, the isotropic material model is accepted as it was done in [22] where the ball burnishing process was simulated. The material constants are: shear module $-4.4 \times 1010[\mathrm{n} / \mathrm{m} 2]$ and Poisson coefficient -0.3 . The stress-strain curve is depicted in Fig. 6. In this work, the measure of compressive residual stress is a hydrostatic component of stress tensor. Calculations were performed for $\mathrm{r}=0.5[\mathrm{~mm} / \mathrm{rev}]$ and $\mathrm{n}=12$; the result is presented in Fig. 7 and agrees with the results on DR [19,21].

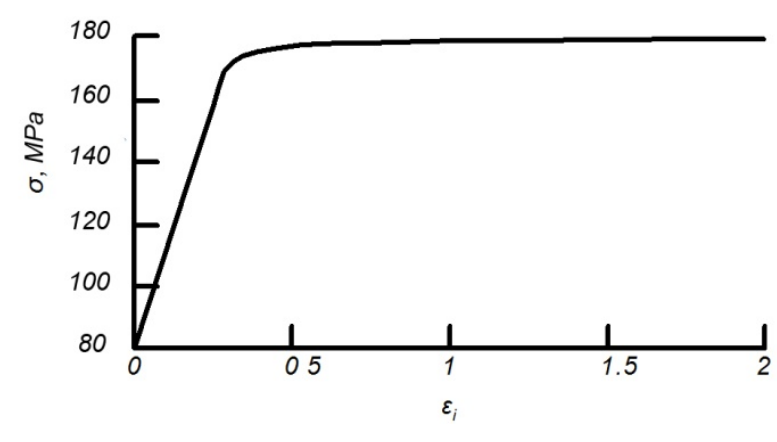

Figure 6. Stress-strain curve of the material

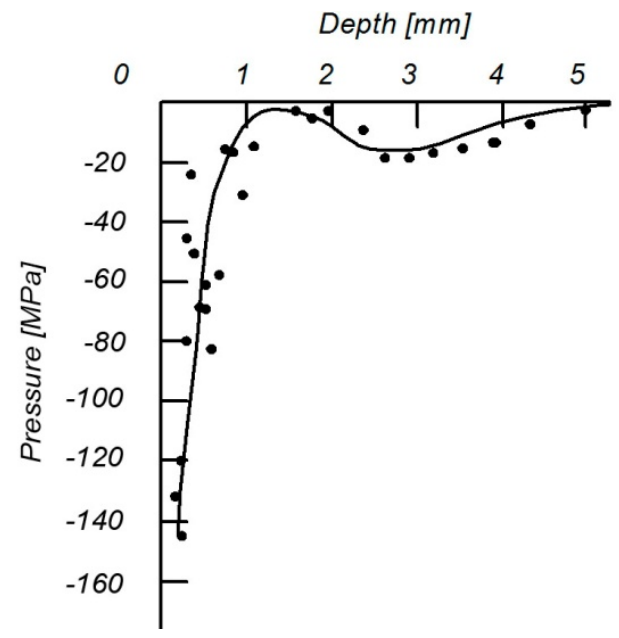

Figure 7. Hydrostatic component of the residual stress tensor 


\subsection{Microstructure}

In cold working hardening processes, two phenomena contribute to the overall effect: strain hardening (due to generation of barriers preventing plastic deformation carrier motion) and global microstructure transformations (i.e. phase transition of second order or mixing of phases of which the material consists), while the latter exceeds the former [24]. The material under investigation possesses a dendrite structure. Hence, one can expect the dendrite grain crumbling at high extent of deformation and thus, to reveal the predominant mechanism of hardening.

The microstructure images was obtained in the crosswise section (i.e., normal to $O$ axis in Fig. 1b) for $n=15$ and $r=0.5[\mathrm{~mm} / \mathrm{rev}]$ and are presented in Figure 8.
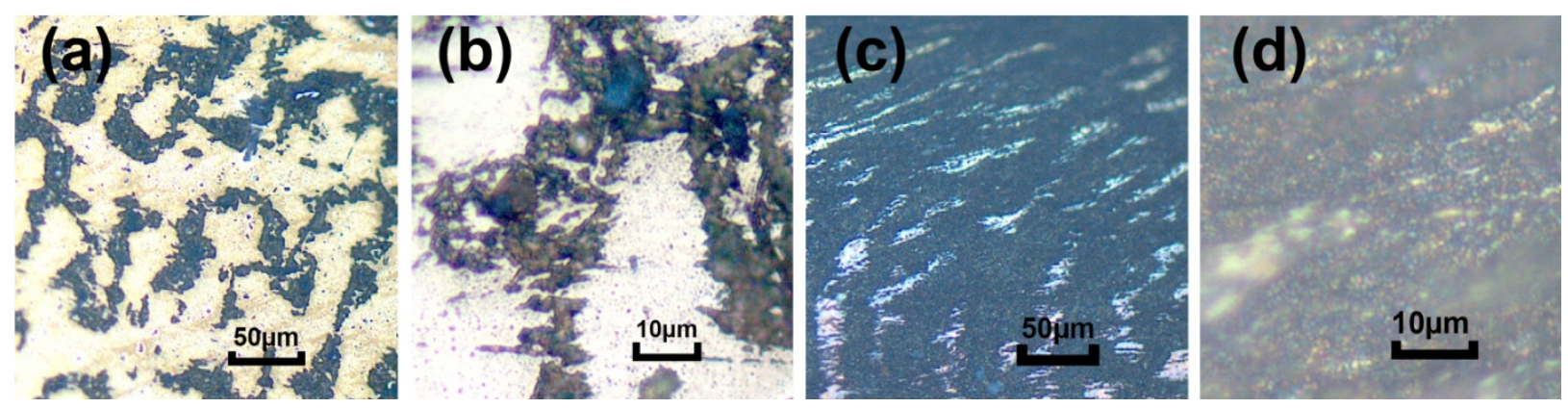

Figure 8. Microstructure in cross section of workpiece: a, $\mathbf{b}$ Virgin material and $\mathbf{c}, \mathbf{d}$ Wrought material in near-surface layer

Here, Figures 8 a, b show the structure of the virgin material. One can see dendrite grains (light) into a solid solution (dark). As was pointed out in Section 2, materials of such a structure are too hard for cold working and the only way to fulfill the working is to create sufficiently large compressive stresses in the course of the process. Under working, dendrite begins to crumble interfusing with a solid solution. Figures $8 \mathrm{c}, \mathrm{d}$ show the region of maximum hardening at depth $0.2 \mathrm{~mm}$, where the dendrite grains are splitted into structural elements of size $100-200 \mathrm{~nm}$. This is in a good agreement with one of the results [25], where aluminum alloy 2014 under ball burnishing process was investigated: the repetition of working passes on the same workpiece leads to an increase in the structural homogeneity which results in an increase in the surface hardness.

\section{Conclusions}

- The newly developed deep rolling - burnishing tool can be used for deep hardening of inner cylindrical surfaces in a time comparable with a time of usual deep rolling at the same number of passes.

- Both out-of-roundness and groove's depth depend appreciably on feed rate.

- Maximum values of hardening and hardened layer depth exceed such values for deep rolling process.

- Hardness gradient is approximately constant and is affected by feed rate; surface hardening value and hardened layer depth are approximately proportional to number of passes.

- Compressive residual stress is generated in near-surface layer during the course of deep rolling - burnishing treatment and 2-D numerical modeling allows assessing this effect in terms of hydrostatic component of stress tensor.

- The microstructure photographies show that deformation causes gradual destruction of dendrite grains, the mixing of dendrite component and solid solution, and microstructure details of small size (100-200 nm) formation; an increase in the structural homogeneity results in an increase in the surface hardness.

\section{Acknowledgements}

The authors would like to thank the financial support of the research from Ministry of Education and Science of Russian Federation under Governmental Order "Scientific-Technological Ground Creation for Hardening Technique by Complex Local Deforming of Assembly Parts in Motor Transport" Number 602.

\section{References}

Abrão, A. M., Denkena, B., Breidenstein, B., \& Mörke, T. (2014). Surface and Subsurface Alterations Induced by Deep Rolling of Hardened AISI 1060 Steel. Prod Eng Res Devel online: 27 March 2014. http://dx.doi.org/10.1007/s11740-014-0539-x 
Akkurt, A. (2011). Comparison of Roller Burnishing and Other Methods of Finishing Treatment of the Surface of Openings in Parts from Tool Steel d3 for Cold Forming. Met Sci Heat Treat, 53, 145-150. http://dx.doi.org/10.1007/s11041-011-9358-2

Akkurt, A. (2011). Comparison of Roller Burnishing Method with Other Hole Surface Finishing Processes Applied on AISI 304 Austenitic Stainless Steel. $J$ Mater Eng Perf., 20, 960-968. http://dx.doi.org/10.1007/s11665-010-9718-x

Bagheri, S., \& Guagliano, M. (2009). Review of Shot Peening Processes to obtain Nanocrystalline Surfaces in Metal Alloys. Surf Eng., 25, 3-14. http://dx.doi.org/10.1179/026708408X334087

Bagherifard, S., Ghelichi, R., \& Guagliano, M. (2010). A Numerical Model of Severe Shot Peening (SSP) to predict the Generation of a Nanostructured Surface Layer of Material. Surf Coat Technol, 204, 4081- 4090. http://dx.doi.org/10.1016/j.surfcoat.2010.05.035

Brinksmeier, E., Garbrecht, M., \& Meyer, D. (2008). Surface hardening by strain induced martensitic transformation. Prod Eng Res Dev, 2, 109-116. http://dx.doi.org/10.1007/s11740-007-0060-6

Brinksmeier, E., Garbrecht, M., Meyer, D., \& Dong, J. (2008). Surface hardening by strain induced martensitic transformation. Prod Eng Res Devel, 2, 109-116. http://dx.doi.org/10.1007/s11740-007-0060-6

Child, D. J., West, G. D., \& Thomson, R. C. (2011). Assessment of Surface Hardening Effects from Shot Peening on a Ni-based Alloy using Electron Backscatter Diffraction Techniques. Acta Mater, 59, 4825-4834. http://dx.doi.org/10.1016/j.actamat.2011.04.025

Cho, K. T., Song, K., Oh, S. H., Lee, Y. K., Lim, K. M., \& Lee, W. B. (2012). Surface Hardening of Aluminum Alloy by Shot Peening Treatment with Zn Based Ball. Mater Sci Eng A, 543, 44-49. http://dx.doi.org/10.1016/j.msea.2012.02.043

Dai, K., \& Shaw, L. (2007). Comparison between Shot Peening and Surface Nanocrystallization and Hardening Processes. Mater Sci Eng A, 463, 46 -53. http://dx.doi.org/10.1016/j.msea.2006.07.159

El-Axir, M. H., Othman, O. M., \& Abodiena, A. M. (2008). Improvements in out-of-roundness and microhardness of inner surfaces by internal ball burnishing process. J Mat Proc Tech, 196, 120-128. http://dx.doi.org/10.1016/j.jmatprotec.2007.05.028

Guan, R., Wang, X., Zhao, Z., Wang, W., Cao, F., \& Liu, C. (2013). Microstructure and Properties of A2017 Alloy Strips Processed by a Novel Process by Combining Semisolid Rolling, Deep rolling, and Heat Treatment. Int J Miner Metall Mater, 20, 770-778. http://dx.doi.org/10.1007/s12613-013-0795-3

Hamadache, H., Zemouri, Z., Laouar, L., \& Dominiak, S. (2014). Improvement of Surface Conditions of $36 \mathrm{Cr} \mathrm{Ni}$ Mo 6 Steel by Ball Burnishing Process. $J$ Mech Sci Technol, 28, 1491-1498. http://dx.doi.org/10.1007/s12206-014-0135-1

Juijerm, P., \& Altenberger, I. (2007). Effect of High-Temperature Deep Rolling on Cyclic Deformation Behavior of Solution-Heat-Treated $\mathrm{Al}-\mathrm{Mg}-\mathrm{Si}-\mathrm{Cu}$ alloy. $J$ Script Materialia, 56, 285-288. http://dx.doi.org/10.1016/j.scriptamat.2006.10.017

Majzoobi, G. H., Azadikhah, K., \& Nemati, J. (2009). The Effects of Deep Rolling and Shot Peening on Fretting Fatigue Resistance of Aluminum-7075-T6. Mater Sci Eng A., 516, 235-247. http://dx.doi.org/10.1016/j.msea.2009.03.020

Majzoobi, G. H., Motlagh, S. T., \& Amiri, A. (2010). Numerical Simulation of Residual Stress Induced by Roll-Peening. Trans Indian Inst Met, 63, 499-504. http://dx.doi.org/10.1007/s12666-010-0071-4

Meyer, D., E Brinksmeier, E., \& Hoffmann, F. (2011). Surface hardening by cryogenic deep rolling. Procedia Eng., 19, 258 -263. http://dx.doi.org/10.1016/j.proeng.2011.11.109

Morrev, P. G. (2011). A Variational Statement of Quasistatic "Rigid-Deformable" Contact Problems at Large Strain Involving Generalized Forces and Friction. Acta Mech, 222, 115-130. http://dx.doi.org/10.1007/s00707-011-0516-9

Nalla, R. K., Altenberger, I., Noster, U., Liu, G. Y., Scholtes, B., \& Ritchie, R. O. (2003). On the Influence of Mechanical Surface Treatments-Deep Rolling and Laser Shock Peening-on the Fatigue Behavior of Ti-6Al-4V at Ambient and Elevated Temperatures. Mater Sci Eng A., 355, 216-230. http://dx.doi.org/10.1016/S0921-5093(03)00069-8

Richards, M. D., Burnett, M. E., Speer, J. G., \& Matlock, D. K. (2013). Effects of Deformation Behavior and 
Processing Temperature on the Fatigue Performance of Deep-Rolled Medium Carbon Bar Steels. Metallurg Mat Trans A, 44, 270-285. http://dx.doi.org/10.1007/s11661-012-1371-6

Sayahi, M., Sghaier, S., \& Belhadjsalah, H. (2013). Finite Element Analysis of Ball Burnishing Process: Comparisons Between Numerical Results and Experiments. Int J Adv Manuf Technol, 67, 1665-1673. http://dx.doi.org/10.1007/s00170-012-4599-9

Tadic, B., Todorovic, P., Luzanin, O., Miljanic, D., Jeremic, B., Bogdanovic, B., \& Vukelic, D. (2013). Using Specially Designed High-stiffness Burnishing Tool to Achieve High-quality Surface Finish. Int J Adv Manuf Technol, 67, 601-611. http://dx.doi.org/10.1007/s00170-012-4508-2

Wong, C. C., Hartawana, A., \& Teoa, W. K. (2014). Deep Cold Rolling of Features on Aero-Engine Components. Procedia CIRP, 13, 350-354. http://dx.doi.org/10.1016/j.procir.2014.04.059

Xie, J., Zhu, Y., Huang, Y., Bai, C., \& Ye, X. (2013). Microstructure Characteristics of 30CrMnSiNi2A Steel After Ultrasound-Aided Deep Rolling. $J$ Mater Eng Perf., 22, 1642-1648. http://dx.doi.org/10.1007/s11665-012-0459-x

Yilmaz, S. S., \& Varol, R. (2010). The effect of Surface Hardening Treatments on the Mechanical Properties of Iron Based P/M Specimens. Powd Technol, 204, 236 -240. http://dx.doi.org/10.1016/j.powtec.2010.08.007

\section{Copyrights}

Copyright for this article is retained by the author(s), with first publication rights granted to the journal.

This is an open-access article distributed under the terms and conditions of the Creative Commons Attribution license (http://creativecommons.org/licenses/by/3.0/). 